\title{
NARZĘDZIA KRYTYCZNEGO MYŚLENIA NA LEKCJI JEZYKA POLSKIEGO JAKO OBCEGO W DOBIE EDUKACJI ZDALNEJ
}

\begin{abstract}
Słowa kluczowe: krytyczne myślenie, edukacja zdalna, rutyny krytycznego myślenia, budowanie rusztowania, społeczność uczących się

Streszczenie. Autorka artykułu koncentruje się w tekście na wykorzystaniu popularnych w ostatnim czasie w dydaktyce narzędziach krytycznego myślenia (oddzielając jednocześnie owe narzędzia od critical thinking) na lekcji języka polskiego jako obcego w dobie edukacji zdalnej, biorąc zarówno pod uwagę kursy online (online teaching), jak i nauczanie zdalne (remote teaching). Za istotne aspekty nauczania zdalnego uznane zostają: budowanie społeczności uczących się (building community of learners), obecność nauczyciela (teaching presence), budowanie rusztowania (scaffolding learning) z wykorzystaniem rutyn krytycznego myślenia. W tekście autorka omawia przykład lekcji języka polskiego jako obcego, podczas której zostały wykorzystane strategie krytycznego myślenia.
\end{abstract}

W 2018 roku Rada Unii Europejskiej na nowo zdefiniowała kompetencje kluczowe, których zakres określono w następujący sposób: rozumienie i tworzenie informacji, wielojęzyczność, matematyka, nauki przyrodnicze, technologia i inżynieria, umiejętności cyfrowe, umiejętność uczenia się, kompetencje osobiste, społeczne i obywatelskie, przedsiębiorczość, świadomość i ekspresja kulturalna. Analiza każdej z kompetencji kluczowych prowadzi do wniosku, że niezbędną umiejętnością umożliwiającą rozwijanie każdej z nich jest krytyczne myślenie. Kompetencje kluczowe zostały wpisane w koncepcję life long learning, powinny stanowić efekt uczenia się uzyskany w edukacji formalnej, pozaformalnej i nieformalnej (Kwiatkowski 2018:16). Niemożliwe jest dziś zdobywanie

*irena.chawrilska@ug.edu.pl, Uniwersytet Gdański, Wydział Filologiczny, Zakład Polonistyki Stosowanej, Instytut Filologii Polskiej, ul. Wita Stwosza 55, 80-308 Gdańsk. 
wiedzy, umiejętności i kompetencji społecznych, jeśli nasze myślenie nie jest zdyscyplinowane i nie staramy się przeprowadzać rozumowań na najwyższym poziomie, w sposób uczciwy intelektualnie, poszukując logicznych uzasadnień naszych sądów.

Sytuacja skomplikowała się jeszcze bardziej wraz z nadejściem pandemii Covid-19, która zmieniła obraz edukacji na świecie. Placówki oświatowe zamknięto, a cele edukacyjne zaczęto realizować w środowisku elektronicznym za pomocą kursów online lub zdalnego nauczania. Uczący stosują różnorodne formy mające na celu wspieranie uczących się. Istotniejszą niż dotychczas umiejętnością stało się prowadzenie dialogu motywującego, praca z uczącymi w taki sposób, żeby byli oni gotowi określić cele, a następnie - realizować je w nowej, zmienionej formule. Brak spotkań face à face utrudnia budowanie relacji uczących się z uczącymi, co również utrudnia naukę krytycznego myślenia. Edukatorzy w dobie edukacji zdalnej mają mniejsze możliwości dyskutowania, wspólnego analizowania źródeł ze swoimi uczniami. Trudniej zorganizować autentyczną dyskusję, rozmowę, w której można autentycznie dialogować i postępować na drodze krytycznego myślenia. W niniejszym tekście analizie zostaje poddana lekcja zdalna, choć równie ciekawa mogłaby się okazać analiza podobnych zajęć przeprowadzonych w trybie stacjonarnym.

\section{KRYTYCZNE MYŚLENIE A NARZĘDZIA KRYTYCZNEGO MYŚLENIA}

Krytyczne myślenie może dziś wydawać się kategorią wytartą, nadużywaną w różnych kontekstach, nie tylko edukacyjnych. Pojęcie to bywa rozumiane zbyt szeroko za sprawą popularności anglosaskiego nurtu critical thinking. Na ogół oznacza pewną formę logiki praktycznej, która koncentruje się na analizie argumentacji codziennych oraz na wypracowywaniu postaw i nabywaniu umiejętności będących efektem stosowania logiki w praktyce (por. Ennis 1996, Będkowski 2019). Zgodnie z definicją zawartą w Wielkim słowniku języka polskiego słowo krytyczny pochodzi od greckiego gr. kritikós 'osądzający', a jego znaczenie jest związane $\mathrm{z}$ umiejętnością dokonywania krytyki - działania polegającego na tym, że postrzega się jakąś rzecz lub zjawisko z wykorzystaniem różnorodnych kryteriów, aby następnie ocenić je jako całość lub ze wskazaniem na poszczególne elementy (WSJP 'krytyczny'). Na tym polega praca krytyka sztuki, kulinarnego czy filmowego, który analizuje i ocenia zgodnie z przyjętymi kryteriami. Wydawanie krytycznych sądów wymaga bowiem przyjęcia jakiegoś kryterium, oparcia na jakiejś zasadzie innej niż tylko osobiste upodobanie. Myślenie krytyczne to myślenie zgodne z wyraźnymi i dobrymi 
kryteriami, a jednocześnie myślenie świadome tego, z jakich kryteriów korzysta ${ }^{1}$. Tego rodzaju myślenie jest dziś w dobie pandemii i nieustannie pojawiających się fake newsów nadzwyczaj ważną umiejętnością, szczególnie w czasie edukacji zdalnej. Osoby myślące krytycznie podejmują bowiem starania, by żyć racjonalnie i w sposób empatyczny, są uwrażliwione na zawodną naturę ludzkiego myślenia. Używają narzędzi intelektualnych, pracują nad warsztatem krytycznego myślenia, są otwarte na nowe pojęcia i zasady, które umożliwiają analizowanie, ocenianie i logiczne myślenie. Są otwarte na nowe, świadome ułomności swojego umysłu i własnej oceny rzeczywistości, dostrzegają złożoność problemów w społeczeństwie i świecie, starają się unikać uproszczeń, dążą do samodoskonalenia i budowania racjonalnego społeczeństwa obywatelskiego, podzielają przekonanie Sokratesa: „bezmyślnym życiem żyć człowiekowi nie warto"'.

Zastanawiać może, w jaki sposób zmotywować uczących się do krytycznego myślenia na lekcji języka polskiego jako obcego i czy rzeczywiście kontekst glottodydaktyczny jest tym właściwym do rozwijania tej umiejętności zarówno w grupie dorosłych, jak i uczniów z doświadczeniem migracyjnym. Zakładając, że uczący języka polskiego jako obcego realizują program zgodny z Europejskim Systemem Opisu Kształcenia Językowego, należy zaznaczyć, że w dokumencie tym, oprócz usystematyzowanych opisów poziomów znajomości języków, znajdziemy treści ukierunkowujące na działania promujące wielokulturowość iróżnojęzyczność. WESOKJ wykorzystanokoncepcjękompetencji interkulturowej Michaela Byrama (1997), w Common European Framework of Reference for Languages. Learning, Teaching, Assessment. Companion Volume with New Descriptors z 2018 zaś uzupełniono skale opisów poziomów języka o deskryptory mediacji, koncepcje mediacji, skale dla strategii mediacji kompetencji różnojęzycznych i różnokulturowych. Celem nauczania języka i kultury we współczesnym świecie jest kompetencja międzykulturowa (Miodunka, Gębal 2020) rozumiana jako typ wrażliwości rodzącej się w wyniku świadomości rozumienia relacji (podobieństw i wyraźnych różnic) między kulturą pochodzenia a kulturą języka docelowego. Kompetencja ta rośnie wraz z poznawaniem coraz większej liczby języków obcych, ponieważ języki i kultury są umieszczane w coraz szerszym kontekście kulturowym. Kompetencja kulturowa to doskonała znajomość języka obcego i danej kultury, kompetencja interkulturowa - to doskonała znajomość dwóch kultur, umożliwiająca ich porównywanie, wskazywanie różnic oraz zastosowanie tej wiedzy w czasie aktu komunikacji. Specyficzna świadomość metakulturowa obejmująca naturę i mechanizmy funkcjonowania kultury to kompetencja transkulturowa, która jest niemożliwa do osiągnięcia bez krytycznego namysłu nad przejawami działań kulturowych i prób ich interpretacji oraz

\footnotetext{
${ }^{1}$ http://www.criticalthinking.pl/wprowadzenie/ (dostęp: 05.05.2021).

${ }^{2}$ http://www.criticalthinking.pl/czym-jest-krytyczne-myslenie/ (dostęp: 05.05.2021).
} 
mediacji interkulturowej, która umożliwia zrównoważoną interakcję nakierowaną na usuwanie barier komunikacyjnych i wzajemne bogacenie się.

Umiejętność rozumienia mechanizmów innej kultury i mediowania między kulturami wymaga nieakceptowania przekonań, dla których nie mamy dostatecznego uzasadnienia. Postulat krytycznego myślenia zawarty w zasadzie dostatecznej racji naruszamy m.in. przez lekkomyślne dawanie wiary cudzym słowom i wskutek wpływu, jaki mają nasze uczucia i pragnienia na nasze przekonania (zob. Będkowski 2020). Mimo bogatej tradycji krytycznego myślenia na gruncie polskim w Szkole Lwowsko-Warszawskiej, w której koncepcja logiki ogólnej opierała się na postulatach krytycyzmu i jasności, a jej badacze i nauczyciele przypisywali logice ogólnej duże znaczenie związane $\mathrm{z}$ przeświadczeniem o silnej potrzebie kształtowania kultury logicznej w społeczeństwie (Będkowski 2020, 173), dziś nie jesteśmy w stanie wykorzystać osiągnięć SLW w edukacji bez udziału merytorycznie przygotowanych filozofów i świadomych uczniów zmotywowanych do pracy $\mathrm{w}$ tym zakresie. $\mathrm{Z}$ pomocą przychodzą nam jednak narzędzia krytycznego myślenia, czyli proste narzędzia wspierające myślenie, strategie, dzięki którym uczący się wspólnie lub indywidualnie inicjują dyskusje, badają dyskursy, dyskutują i - co najważniejsze - zarządzają swoim myśleniem. Rutyny krytycznego myślenia mogą być wykorzystywane podczas każdego rodzaju zajęć dydaktycznych, żeby wspierać uczącego się w kształtowaniu logicznego myślenia i pogłębianiu refleksji. Można do nich zaliczyć: narzędzia TOC Elliego Goldrata, mapy rozwiązywania problemów dr Danilo Siriasa, model Vess amerykańskiej firmy Edu1st, Project Zero z Harvard University. Narzędziami myślowymi mogą być: mapy, grafy, tabele, organizery, schematy wizualne, zestawienia ${ }^{3}$, a do najbardziej popularnych rutyn MK należą: winda - w 60 sekund przekonaj mnie, że..., Double Bubble: znajdź i pokaż zależności, powiązania, analogie, różnice, MOST: 3 słowa, 2 pytania, 1 porównanie/metafora (hasło), koło punktów widzenia: wejdź w sposób myślenia konkretnej osoby, 12 pytań sokratejskich do..., 5xdlaczego - uświadom sobie głęboką przyczynę, Chalk Talk: argument-kontrargument, Widzę, myślę, zastanawiam się. Każda z rutyn wizualizuje analizowany problem, a tym samym ułatwia kategoryzowanie, dostrzeganie reguł i syntetyzowanie, ułatwia wyciąganie wniosków przez uczących się i rozwiązywanie postawionych problemów.

\section{E-LEARNING, ONLINE LEARNING, REMOTE LEARNING}

Nauczanie zdalne (remote learning) różni się w swojej istocie i założeniach od nauczania online czy kursów e-learningowych. Za definicję ostatniego z wymienionych pojęć należy uznać nauczanie prowadzone za pośrednic-

\footnotetext{
${ }^{3}$ https://mysleniekrytyczne.edu.pl/co-to-sa-narzedzia-krytycznego-myslenia/ (dostęp: 10.05.2021).
} 
twem mediów elektronicznych, zazwyczaj w Internecie. Proces ten powinien być sformalizowany i przebiegać $\mathrm{z}$ wykorzystaniem sprzętu komputerowego oraz narzędzi cyfrowych, platform internetowych, elektronicznych materiałów edukacyjnych umożliwiających transfer umiejętności i wiedzy. Nauka online odbywa się również z użyciem komputerów, tabletów, smartfonów i narzędzi internetowych. Główna różnica w stosunku do e-learningu polega na tym, że nauczanie online opiera się wyłącznie na narzędziach cyfrowych dostępnych za pośrednictwem Internetu. W związku z tym nauka online jest uważana za realną alternatywę dla studiów stacjonarnych, ponieważ oferuje możliwość uczenia się w odległych miejscach i instytucjach dydaktycznych. Nauczanie zdalne natomiast odbywa się fizycznie poza klasą. Uczący się są oddzieleni od uczących, a kontakt między nimi jest możliwy za pośrednictwem oprogramowania do wideokonferencji, tablic dyskusyjnych lub innych systemów zarządzania nauką. Ten rodzaj nauczania może odbywać się synchronicznie, gdy edukatorzy prowadzą zajęcia na żywo, lub asynchronicznie, gdy studenci po fakcie wracają do nagranych zajęć. Bez względu na przyjęty rodzaj nauki na odległość przed edukatorami stoją podobne wyzwania, dlatego niezwykle istotnym aspektem nauki na odległość jest zaprojektowanie kursu, w którym uczący jest obecny podczas całego procesu dydaktycznego, wspiera społeczność uczących się i daje im narzędzia pozwalające na „budowanie rusztowania” i w efekcie - pracę samodzielną. Uczący, który świadomie planuje swoją pracę dydaktyczną, jest już obecny na etapie projektowania kursu i planowania dydaktycznego, kontynuuje swoją pracę w trakcie kursu, kiedy udziela bezpośrednich instrukcji w razie potrzeby (Anderson $i$ in. 2001). Instruktaż edukatora polega na budowaniu rusztowania, czyli wykorzystywaniu takiej metody uczenia, która prowadzi uczniów do większej niezależności i zrozumienia podczas procesu uczenia się (Shaw 2019). Budując rusztowanie, uczący przekazuje odpowiedzialność za proces uczenia się studentom, co w założeniu powinno prowadzić do zawiązania społeczności uczniów, wspólnie angażujących się w krytyczny dyskurs i refleksję w celu skonstruowania znaczenia i potwierdzenia zrozumienia poszczególnych zjawisk czy zagadnień (Garrison 2007). Rutyny krytycznego myślenia są skutecznymi narzędziami $\mathrm{w}$ dobie edukacji prowadzonej $\mathrm{z}$ wykorzystaniem technik uczenia na odległość, w dobie pandemii Covid-19, ponieważ motywują i inspirują uczących się do samodzielnego sprawdzania faktów, analizowania, stawiania hipotez i ich weryfikowania, tworzenia logicznych powiązań, rozwiązywania problemów, rozpoznawania emocji u siebie i innych, myślenia o myśleniu, kwestionowania własnych założeń i przewidywania konsekwencji wydarzeń i decyzji. 


\section{PALENIE KSIAZŻEK W GDAŃSKU}

Sytuacja, która została omówiona na zajęciach ze studentami i kursantami ${ }^{4}$, miała miejsce 31.03.2019 r w Parafii NMP Matki Kościoła i św. Katarzyny Szwedzkiej w Gdańsku. Co właściwie się wydarzyło? Podczas rekolekcji wielkopostnych księża, służba liturgiczna i wierni wyszli przed kościół i spalili kilkanaście książek, m.in. Harry'ego Pottera i Zmierzch, maski, amulety i różową parasolkę z bajkową postacią Hello Kitty. Zdjęcia z przebiegu wydarzenia zostały opublikowane na profilu facebookowym SMS z Nieba. Post na Facebooku nie ograniczał się tylko do elementów wizualnych, czyli zdjęć z wydarzenia, został również opatrzony komentarzem słownym, który składał się z cytatów z Biblii: „Posągi ich bogów spalisz, nie będziesz pożądał srebra ani złota, jakie jest na nich, i nie weźmiesz go dla siebie, aby cię to nie uwikłało, gdyż Pan, Bóg twój, się tym brzydzi” (Pwt 7, 25), „Duża liczba uprawiających magię przynosiła swe księgi i palił je wobec wszystkich” (Dz 19, 19a); z cytatów z Katechizmu Kościoła Katolickiego: „Należy odrzucić wszystkie formy wróżbiarstwa: odwoływanie się do Szatana lub demonów, przywoływanie zmarłych lub inne praktyki mające rzekomo odsłaniać przyszłość (por. Pwt 18, 10; Jr 29, 8). Korzystanie z horoskopów, astrologia, chiromancja, wyjaśnianie przepowiedni i wróżb, zjawiska jasnowidztwa, posługiwanie się medium są przejawami chęci panowania nad czasem, nad historią i wreszcie nad ludźmi, a jednocześnie pragnieniem zjednania sobie ukrytych mocy. Praktyki te są sprzeczne ze czcią i szacunkiem - połączonym z miłującą bojaźnią - które należą się jedynie Bogu” (KKK 2116), „Wszystkie praktyki magii lub czarów, przez które dąży się do pozyskania tajemnych sił, by posługiwać się nimi i osiągać nadnaturalną władzą nad bliźnim - nawet w celu zapewnienia mu zdrowia - są w poważnej sprzeczności z cnota religijności. Praktyki te należy potępić tym bardziej wtedy, gdy towarzyszy im intencja zaszkodzenia drugiemu człowiekowi lub uciekanie się do interwencji demonów. Jest również naganne noszenie amuletów. Spirytyzm często pociąga za sobą praktyki wróżbiarskie lub magiczne. Dlatego Kościół upomina wiernych, by wystrzegali się ich. Uciekanie się do tak zwanych tradycyjnych praktyk medycznych nie usprawiedliwia ani wzywania złych mocy, ani wykorzystywania łatwowierności drugiego człowieka" (KKK 2117) oraz tekstu autorskiego: Ks. Gabriel Amorth, ks. Olszewski - wprost przestrzegają przed tym, by uważać, co się czyta, ponieważ wpływa to na nas i na nasze postrzeganie świata ${ }^{5}$. Post odbił się

${ }^{4}$ Zajęcia zdalne przeprowadzono wiosną 2021 r. ze studentami z Harbinu studiującymi w Instytucie Filologii Polskiej Uniwersytetu Gdańskiego oraz z kursantami uczestniczącymi w kursach z języka polskiego organizowanych przez Akademickie Centrum Języka Polskiego i Kultury Polskiej dla Cudzoziemców na Uniwersytecie Gdańskim (poziom B1).

${ }^{5}$ Ten post został usunięty z Facebooka, zob. https://deon.pl/kosciol/przed-kosciolem-spalili-ksiazki-o-harrym-potterze-to-wierni-je-przyniesli-bo-nadszedl-czas-zeby-zrobic-z-tym-porzadek,514248 (dostęp: 20.04.2021). 
szerokim echem w mediach krajowych i zagranicznych ${ }^{6}$. Proboszcz parafii zapytany o tę sytuację, miał odpowiedzieć: „To nie było palenie jakichś tam książek, ale palenie przedmiotów związanych z magią i okultyzmem. Oprócz książek były tam także inne przedmioty - amulety, talizmany. To wierni je przynieśli, bo nadszedł czas, żeby zrobić z tym porządek" " Zdaniem księdza proboszcza wierni spalili przedmioty, ponieważ nabyli świadomości, że posiadają przedmioty magiczne, a ks. Rafał Jarosiewicz, który brał czynny udział w wydarzeniu przed gdańską świątynią, skomentował je na swoim profilu facebookowym w następujący sposób: „Marzy mi się taki czas, kiedy ludzie w proteście przeciw zabijaniu nienarodzonych dzieci, będą reagować choć w połowie tak gorliwie, jak na spalenie książek o magii..."». Wydarzenia z Gdańska komentowano bardzo różnie, nazywając je bezdenną głupotą, kroplą przelewającą czarę, gusłem, średniowiecznym przesądem, głupotą, zostały skojarzone z Inkwizycją, Trzecią Rzeszą i ZSRR ${ }^{9}$. Ostatecznie ksiądz został ukarany mandatem przez straż miejską, a prezes Fundacji SMS Z NIEBA opublikował na profilu facebookowym Fundacji oświadczenie o następującej treści: „Fakt spalenia książek i innych przedmiotów był niefortunny. Nie miał on jednak charakteru prześmiewczego wobec jakiejkolwiek grupy społecznej czy religii, nie był też wymierzony w książki jako takie czy kulturę. Jeśli ktokolwiek moje działania odebrał w ten sposób, chciałbym w tym miejscu go bardzo serdecznie przeprosić. Fundacja przez ostatnie pięć lat rozdała za darmo prawie ćwierć miliona książek, w tym też książki, które uratowaliśmy przed zniszczeniem w sytuacji likwidacji magazynów przez wydawnictwa. Niefortunna była także publikacja fotografii ukazujących zniszczenie książek i innych przedmiotów dobrowolnie przyniesionych przez uczestników rekolekcji, zwłaszcza że nie zawierała żadnych wyjaśnień. Informujemy też, że usuwamy z naszego profilu zamieszczony materiał, by nie generował kolejnych emocji. Jeszcze raz bardzo przepraszam"10.

${ }^{6}$ Zob. https://tvn24.pl/pomorze/palenie-ksiazek-przed-kosciolem-w-gdansku-harry-potter -ma-zla-moc-ra923499-2294088, https://wiadomosci.onet.pl/trojmiasto/gdansk-palenie-ksiazek -w-gdansku-ksiadz-dostal-mandat-sprawa-w-prokuraturze/fk2yelz, https://wiadomosci.wp.pl/ bbc-napisalo-o-paleniu-ksiazek-przez-ksiezy-w-gdansku-6365714519611521a, https://natemat. pl/268573,ksieza-palili-ksiazki-w-gdansku-wzial-ich-na-celownik-zastepca-dulkiewicz, https:// wiadomosci.onet.pl/kraj/palenie-ksiazek-przez-ksiezy-i-ministrantow-swiatowe-media-komentuja/zxrkrsd?utm_source=wiadomosci.onet.pl_viasg_wiadomosci\&utm_medium=referal\&utm campaign=leo_automatic\&srcc $=$ ucs\&utm_v=2 (dostęp: 05.05.2021).

${ }^{7}$ Zob. https://deon.pl/kosciol/przed-kosciolem-spalili-ksiazki-o-harrym-potterze-to-wierni-je -przyniesli-bo-nadszedl-czas-zeby-zrobic-z-tym-porzadek,514248 (dostęp: 05.05.2021).

${ }^{8}$ Ibid.

9 https://wiadomosci.onet.pl/kraj/palenie-ksiazek-przez-ksiezy-i-ministrantow-swiatowe-media-komentuja/zxrkrsd?utm_source=wiadomosci.onet.pl_viasg_wiadomosci\&utm_medium=referal\&utm_campaign=leo_automatic\&srcc=ucs\&utm_v=2 (dostęp: 06.05.2021).

${ }^{10}$ https://wiadomosci.onet.pl/trojmiasto/gdansk-palenie-ksiazek-w-gdansku-ksiadz-dostal -mandat-sprawa-w-prokuraturze/fk2yelz (dostęp: 10.05.2021). 


\section{LEKCJA JEZZYKA POLSKIEGO A KRYTYCZNE MYŚLENIE}

Impulsem do przeprowadzenia zajęć dotyczących wydarzenia sprzed gdańskiej świątyni stało się pytanie, które zadał student podczas zajęć dotyczących redagowania recenzji książki: „Dlaczego Polacy palą książki?”. Lekcja została przeprowadzona $\mathrm{w}$ kilku grupach, wzięło $\mathrm{w}$ niej udział: szesnaścioro studentek i studentów z Chin oraz dwadzieścioro troje kursantek i kursantów, wśród których byli zarówno Słowianie, jak i przedstawiciele innych grup językowych. Przedmiotem zajęć uczyniono dwie fotografie, zamieszczone pierwotnie na Facebooku Fundacji SMS Z NIEBA, przedstawiające księdza ze służbą liturgiczną modlącego się nad ogniskiem oraz zbliżenie palonych przedmiotów. $Z$ uwagi na to, że lekcja miała dotyczyć przekazu wizualnego (medialnego), za adekwatną metodę pracy uznano strategie myślenia wizualnego, które już od lat osiemdziesiątych są wykorzystywane na lekcjach języków obcych, skutecznie pomagają w rozwoju krytycznego myślenia, alfabetyzmu wizualnego i komunikacji. Uczestniczki i uczestnicy zajęć (6 osób) zobaczyli na ekranach swoich urządzeń elektronicznych omawiane fotografie i 3 pytania:

1. Co dzieje się na tej fotografii?

2. Co widzisz?

3. Co jeszcze możesz znaleźć na zdjęciu?

Odpowiedzi były następujące (przykłady):

1. Mężczyzna pali ogień, pan księż stoi, nie wiem, nie rozumiem, to dziwne

2. Widze zapalone ksiażek, ksiadz i dzieci, Widze Harry Pottera w ognisku

3. Ksiądz stoi i zapalit książki, mężczyzna zanieczyszczuje powietrze, mężczyzna powoduje smog

Uczestnicy zajęć z trudem odpowiadali na postawione pytania, więc pozostałym grupom zaproponowano inne ćwiczenie - rutynę krytycznego myślenia WIDZE, MYŚLE, ZASTANAWIAM SIĘ. Okazało się, że tym razem uczestnicy zajęć chętniej formułowali odpowiedzi, zadanie było dla nich łatwiejsze pod względem językowym, mimo że również musieli zmierzyć się z trudnym materiałem ikonicznym. Uczący się raportowali, że nie wiedzą, co widzą; nie rozumieją tej sytuacji i zastanawiają się, o co chodzi, akcentując przy tym problem zanieczyszczenia środowiska.

Zrealizowanie ćwiczenia z wykorzystaniem rutyny krytycznego myślenia umożliwiło wstępną analizę sytuacji przedstawionej na fotografii. Następnie przyszedł czas na pięć pytań pogłębionych, dzięki którym możliwa miała się okazać interpretacja fotografii i samego wydarzenia. Poniżej przedstawione zostały odpowiedzi uczestniczek i uczestników zajęć na zadane im pytania (odpowiedzi powtarzające się nie zostały uwzględnione). 


\section{CO WIDZISZ NA FOTOGRAFII?}

Ludzie zapalają książki / Na fotografii widzę zapalone książek, ksiadz i dzieci/ 3 osoby / Widzę ksiadza, dzieci i palone ksiązki / Widzę ksiadza, dzieci dziwaczny rzecz i ogien / Widzę ludzie i ksiądz, modla i pala ksiązki przy kościele / Palenie ksiażek / ksiądz w białej stoi przed stosem płonących książek / Palenie ksiązek przez księdza, $i$ dzieci stoja obok modla się / Widze wiele spalonych ksiażek, a ksiadz i dzieci sa przed tymi książami/ ksiądz pali książki i modli się/ Modli ludzi się na plener. Książki zostały zapalone na popiót / Widzę, że ksiądz z dziecmi pala ksiązki i modla / Fotografia przedstawia kilka osób i pala książki i inne przedmioty / Widzę spalone rzeczy / Na zdjęciu widzę sytuacje, gdzie ksiadz z dziecmi spalaja różne rzeczy / Widze na zdjecie księdza ktury publiczno pali ksązki w kturych opisana magia. Dwa chłopca za tym oglądaje / Widzę księdza oraz dwóch chtopców. Oni palia różne rzecze, jaki sa zwiąane z magiją / Ksiadz pali wiele rzeczy. Na przyktad książki, maski, przedmioty, które sa połaczone z innymi religiami lub przekonaniami / ogień, ksiądz, dzieci, trawa, biedny osób / auto / mieszkanie / stoer / peleryna / Widzę ksiadza, który pali książki magiczne, maski, parasoli / Palenie różnych książek i przedmioty

\section{JAK MYŚLISZ, JAKIE WYDARZENIE ZOSTAŁO SFOTOGRAFOWANE?}

Wielki Post / W czasie Wielkego Postu w Gdansku ksiadz palit książki, które dotyczajace o magii / pala ksiązki / Myślę, że to prawdopodobnie jakaś uroczystość / palić przeciw książka / religijne, dziwne, niezgodne z współczesnościa / Myślę, że czlowiek, który robil fotografie, chce rozpowszechniać takie wydarzenie, czyli palenie książek / Treść książki narusza religię, obrzędanie / rekolekcje / Myślę, że oni odbywają się dziwa uroczystość / Książki, które byli spaline sa przeciw religię. Więc ksiądz pali ksiązki / Pod czas rekolekcji ludzie przyniesty rzeczy od których chceli się uwolnić i spality ich obok kościoła / Rekolekcja przed wielkanocka / Zostało sfotografowane wydarzenie gdy coś prywatnie księz pali / Palenie ksiązek oraz innych rzecze / To było w rekolekcje / Ksiadz palenie książki, że on myśli sa zły i nie christianen. On chca przekonać dzieci, że tylko christianen drogi jest prawda drogi / Palenie ksiązek zostało sfotografowane / Jak już wiem, że ksiadz płacit pieniadze, miślę, że on robi ceremonie kościelne, żeby zabić złe dusze

3. CZY WIDZIAŁEŚ/WIDZIAŁAŚ TO ZDJĘCIE WCZEŚNIEJ? W JAKIEJ SYTUACJI?

Nie / przez przyjaciótka / Nigdy nie / Nigdy nie widziałam / Nie widziałaś / Tak, szukam filmów o Vampirze. To zdjęcie się pojawito / Wcześniej zdjęcia nie widziawa bo ja nie religijna osoba i ten temat nie aktualny dla mie / Tak widziałam to zdjęcie w gazetach / Ksiadz znale go chłopci czytaja książki, że on nie lubi. Więc on byt zły i myst byt dobrze pomyst palenie tej skiązek, przestraszyć chłopcy

4. CO ROBI KSIĄDZ NA TYM ZDJĘCIU? CO OZNACZA JEGO STRÓJ?

Ksiadz stoi $i$ zapalit ksiązki które zwiazane z magia, oni nie chce ludzie wierza $w$ zła wiarę / Modlit się przed ogniskiem. Złoty nastrój oznaczyt szczęście / palit książki / On się modlit, żeby wyeliminować kulty / zapłon i pali dziwaczny rzecz. Tradycyjna reguła. Ten strój może pomoc ludziom spokój i wesole / On organizuje tę aktywności / Ksiądz modlit się i palit książki. To znaczy szczęśliwość / Oglada palic ksiązę / Modli się, gromadzi ludzi na to wydarzenie. Strój oznacza wesołość szczęścia / Ksiądz głośno zrobit się w związku z paleniem książek przed kościołem / pali ksiażki / On prowadzi proces modlitwy. Jego strój oznacza, że ta modlitwa jest ważna / Trzymaja ręce razem, ulega i modli / Ksiądz modli się / Ksiądz pali ksią̇ki 
i inne przedmioty. On stoi i patrze na. On ma na sobie biata toge i fioletowy szalik / Ksiądz modli się, iego strój oznacza, ze trwa trzecia tydzień wielkiego posta, czas rekolekcji / Ksiądz pali książi i figurki różnych bozków. Wedtug mnie jego strój oznacza radość. Radośc od tego, że oni uwalniaja się od tego, co nie mile i nieprzyjemne dla Boga / Oglada palenie i myslę, ze modli się. Strój ozncza, że jest jakies religijne święto / Jego strój jest specjalny do okazji Wielki Post / Ksią modli się. On nosi ubrania na radości, bo on jest szczęśliwy palenie kultur / Ksiadz pali różne rzeczy, które sa związane z magiej / Strój oznacza coś szczęśliwego, bo ksiądz nosi ten stoa, kiedy jest letary

\section{CO CZUJESZ, KIEDY OGLĄDASZ TĘ FOTOGRAFIĘ?}

Myślę, że oni marnuja książki, czuję żałowanie i palenie książek zanieczyszczuje powietrze, to jest zła sytuacja dla środowiska. Ludzie, którzy widza te wydarzenie i zrobili zdjęcia i upublicznili / Myśle, że w XXI wieku, który jest woln i otwarty pojawiat się taka sytuację to jest skandal. To będzie duży wptyw na wzrost dla dzieci / Czuję się smutna, bo chociaż nie mamy magi na świacie, możemy mieć fantazję / Rozumiem że ludzi w starym wieku sa przerażone o rzeczu nie rozumienie / Czuje się zdziwiona i uważam, że to marnonie ksiązek i zaniecyszczanie powietrza / Faktycznie czuję sie śmiesznie. Myślę, że te wydarzenie nie powinno być publiczne, bo takie wydarzenie nie jest prawdziwy i nie powinien przekazać takie kultury / Myślę, że zachowanie jest bardzo dziwne. Nie zgadzam się z innymi punktami widzenia $i$ niszczę. Wewnętrzne serce jest nietolerancyjne i paranoiczne / Czuję się niedobrze, zdziwiony. Przeszkadzam mi kiedy zobaczyłem to zdjęcie / Uważam, że to może być problemem, bo to ma zły wpływ na myśl ludzi. W tym wspótczesnym swiecie stato się takie wydarzenie, czuję się bardzo dziwnie / nie naturalnie nerwowy, zanieczyszczaja powietrze / Jestem zaskoczony, bo w wspótczesnym społeczeństwie taka sprawa jest zupetnie rzadka i niewiarygodna. Konflikt religijny w Polsce nie jest ostry i nieunikniony, nie wiem dlaczego tak się zdarzyło / Czuję się smutny. Marnują ksiązki / Myślę, że ci ludzie chyba sa szaleni / czuję się strasznie, bo myślę, że ludzie moga akceptować dużo pomyst / Mysle ze w wyniku tego ludzie zrobili się wolni od swoich „problemuw”, tylko to można zrobić w inny sposób, ne spalając tych rzecy i nie robić zdjęć. Ksiazki można oddać innym ludziam / Kiedy ogladam tę fotografię czuję, że ksiadz robi to specjalnie, żeby pokazać ludziom ich grzechy $i$ uwolnienie od nich. Widać, że ksiadz z dziećmi się modliq. W Biblii napisano, ze czary i magija sa obrzydliwe dla Pana Boga. I robia nas dalej od Niego, jego miłości, bo sam szatan przez to działa / Czuję, że dla mnia dziwna ta sytuacja / Sytuacja trochy podobna do akcji ksiażki „,451 stopni Fahrenheita” / Normalnie. Nie jestem zszokowana / Czuję się, że ksiądz powinny czytac więcej historia, wtedy może nie robi coś taki glupi / Czuję styd / Myślę, że to jest dziwny bo tam stoja dzieci też, który nosza różowa albę / To dla mnie gtupie. Osobiście nigdy nie widziałam kraju, w którym religia ma większa moc $w$ Europie, a kościoly sa liczniejsze niż Polska. Ksiądz na tym zdjęciu palit ksiązki. Gdzie pala książki, niebawem ludzi też palic będa. A mnie nie dziwi ten powrót do średniowiecza. Samodzielne myślenie, inteligencja, sity o myślenie... dzieci nie bardzo maja, więc to zły wplyw na dzieci. Zastraszać musza ciemnotę żeby mieć władzę... ludem głupim się latwo steruje

Każda z osób badanych początkowo nie była w stanie wejść w rozmowę na temat zasugerowany przez fotografie. Zastosowanie rutyny krytycznego myślenia WIDZE, MYŚLE, ZASTANAWIAM SIĘ ułatwiło podjęcie refleksji związanej z paleniem książek w Gdańsku zarówno pod względem kulturowym, 
jak i językowym. Czasowniki w pierwszej osobie liczby pojedynczej: widzę, myślę, zastanawiam się, które stały się początkiem zdań formułowanych przez zdających, niejednokrotnie ośmieliły ich do tego, by wyartykułować swoją odpowiedź. Po wstępnej rozmowie uczący się odpowiedzieli na pięć pytań, które okazały się dla nich niemałym wyzwaniem. Uczestniczki i uczestnicy zajęć w znakomitej większości nie mogli zrozumieć sytuacji przedstawionej na zdjęciu bez wprowadzenia kulturowego. Również studenci z Chin, którzy studiują po polsku i realizują liczne zajęcia z historii Polski i kultury polskiej, nie byli w stanie zinterpretować przedstawionych im fotografii. Tylko dwie osoby widziały wcześniej zdjęcia, wszyscy badani opisali własne odczucia w stosunku do sytuacji z fotografii, tylko jedna osoba nie była zaskoczona tym, co zobaczyła i usłyszała wcześniej na temat wydarzenia sprzed gdańskiego kościoła. Brak zanurzenia w tradycji religijnej uniemożliwił uczącym się lekturę komunikatu wizualnego, jego krytyczną ocenę i interpretację. Niezbędna okazała się tu obecność uczącego (teaching presence), który na zajęciach w trybie zdalnym zmotywował uczących się do dyskusji (building a community of learners) $\mathrm{i}$ dał im narzędzia, które umożliwiły im pracę samodzielną - narzędzia krytycznego myślenia (scaffolding learning). Wartością tego rodzaju zajęć jest poznanie nowego elementu kultury polskiej, który bywa uznawany za zbyt polonocentryczny $i$ jest niechętnie podejmowany przez niektórych lektorów języka polskiego. Kościół katolicki, święta katolickie i zwyczaje są jednak nieodzownym elementem naszej tożsamości i bez znajomości leksyki z tego zakresu, tradycji religijnej i zwyczajów, przyjmowany w kulturze polskiej może czuć się nieswojo w różnych sytuacjach komunikacyjnych i kulturowych. Zajęcia z wykorzystaniem narzędzi krytycznego myślenia uświadomiły to uczącej i uczącym się, otwierając jednocześnie pole do rozmów po polsku na istotne tematy: rola książek w świecie dzisiaj, rola kościoła katolickiego w dzisiejszym świecie, publiczne i niepubliczne wydarzenia - jakie treści warto publikować w Internecie, zwyczaje i tabu w różnych tradycjach religijnych, zanieczyszczenie środowiska, zmiany klimatyczne a cele zrównoważonego rozwoju. Nade wszystko zajęcia dotyczące interpretacji fotografii za pomocą narzędzi krytycznego myślenia, mimo ich zdalnego trybu, wpłynęły na podniesienie kompetencji międzykulturowej każdego z uczestników i każdej z uczestniczek.

\section{PODSUMOWANIE}

Dzięki strategiom myślenia krytycznego i odpowiednim pytaniom możemy wspierać proces glottodydaktyczny, rozwój kompetencji kluczowych i efektywną komunikację. Celem zastosowania narzędzi krytycznego myślenia na lekcji języka 
polskiego jest dostrzeżenie nowych perspektyw, różnych punktów widzenia, niuansów, które możemy znaleźć w niemal każdym akcie komunikacji. W świecie wielokulturowym, w którym międzykulturowość jest istotnym zadaniem, uczenie się przez całe życie i rozwijanie kompetencji kluczowych - naszą powinnością, critical thinking i jego strategie odgrywają nadzwyczaj istotną rolę w nabywaniu kompetencji transkulturowej, bez której trudno dziś w świecie zglobalizowanym wieść satysfakcjonujące życie zawodowe i osobiste.

\section{BIBLIOGRAFIA}

Anderson Lorin W., Krathwoh David R., 2001, A taxonomy for learning, teaching, and assessing : a revision of Bloom's taxonomy of educational objectives, Nowy Jork.

Będkowski M, To Teach Critical Thinking and Clear Speaking. Postulates of Criticism and Clarity and the Issue of So Called General Logic, „Studia Semiotyczne - English Supplement” 2020, Vol. XXXI, s. 167-183, DOI: 10.26333/sts.xxxiii2.04

Ennis R.H., 1996, Critical Thinking Dispositions: Their Nature and Assessability, „Informal Logic” $18(2-3)$.

Garrison D.R., 2007, Online Community Of Inquiry Review: Social, Cognitive, And Teaching Presence Issues, https://www.researchgate.net/publication/242682355_Online_community_of_inquiry_review_Social_cognitive_and_teaching_presence_issues (dostęp: 10.05.2021).

Kwiatkowski S., 2018, Kompetencje przyszłości, Warszawa.

Miodunka W., Gębal P., 2020, Dydaktyka i metodyka nauczania języka polskiego jako obcego i drugiego, Warszawa.

Shaw R., Takeuchi Y., Shiwaku K., Fernandez G., Gwee Q., and Yang B., 2009, 1-2-3 of disaster education, Kyoto, Japan.

Netografia

http://www.criticalthinking.pl/wprowadzenie/ (dostęp 05.05.2021).

https://deon.pl/kosciol/przed-kosciolem-spalili-ksiazki-o-harrym-potterze-to-wierni-je-przyniesli -bo-nadszedl-czas-zeby-zrobic-z-tym-porzadek,514248 (dostęp 05.05.2021).

https://mysleniekrytyczne.edu.pl/co-to-sa-narzedzia-krytycznego-myslenia/ (dostęp 10.05.2021).

https://natemat.pl/268573,ksieza-palili-ksiazki-w-gdansku-wzial-ich-na-celownik-zastepca-dulkiewicz (dostęp 05.05.2021).

https://tvn24.pl/pomorze/palenie-ksiazek-przed-kosciolem-w-gdansku-harry-potter-ma-zla-moc -ra923499-2294088 (dostęp 05.05.2021).

https://wiadomosci.onet.pl/kraj/palenie-ksiazek-przez-ksiezy-i-ministrantow-swiatowe-media-komentuja/zxrkrsd?utm_source=wiadomosci.onet.pl_viasg_wiadomosci\&utm_medium=referal\&utm_campaign $=1$ eo_automatic\&srcc $=u c s \& u t m \_v=2($ dostęp 05.05.2021).

https://wiadomosci.onet.pl/trojmiasto/gdansk-palenie-ksiazek-w-gdansku-ksiadz-dostal-mandat -sprawa-w-prokuraturze/fk2yelz (dostęp 05.05.2021).

https://wiadomosci.wp.pl/bbc-napisalo-o-paleniu-ksiazek-przez-ksiezy-w-gdansku -6365714519611521a (dostęp 05.05.2021). 


\section{Irena Chawrilska}

\section{CRITICAL THINKING STRATEGIES IN LESSONS OF POLISH AS A FOREIGN LANGUAGE IN THE AGE OF REMOTE EDUCATION}

Keywords: critical thinking, remote education, critical thinking routines, scaffolding learning, community of learners

Summary. The article focuses on the use of the recently popular tools of critical thinking in didactics (distinguishing the tools from critical thinking) during the lessons of Polish as a foreign language in the era of remote education, taking into account both online teaching and remote teaching. The following are considered important aspects of distance learning: building a community of learners, teaching presence, and scaffolding learning with the use of critical thinking routines. In the text, the author discusses an example of a lesson of Polish as a foreign language, during which critical thinking strategies were used. 
